\title{
Processes governing snow ablation in alpine terrain - detailed measurements from the Canadian Rockies
}

\author{
Michael Schirmer ${ }^{1,2}$ and John W. Pomeroy ${ }^{1}$ \\ ${ }^{1}$ Centre for Hydrology, University of Saskatchewan, Saskatchewan, Canada \\ ${ }^{2}$ WSL Institute for Snow and Avalanche Research SLF, Davos, Switzerland \\ Correspondence: Michael Schirmer (michael.schirmer@slf.ch)
}

Received: 7 May 2018 - Discussion started: 14 May 2018

Revised: 20 September 2019 - Accepted: 17 October 2019 - Published: 13 January 2020

\begin{abstract}
The spatial distribution of snow water equivalent (SWE) and melt are important for estimating areal melt rates and snow-cover depletion (SCD) dynamics but are rarely measured in detail during the late ablation period. This study contributes results from high-resolution observations made using large numbers of sequential aerial photographs taken from an unmanned aerial vehicle on an alpine ridge in the Fortress Mountain Snow Laboratory in the Canadian Rocky Mountains from May to July in 2015. Using structurefrom-motion and thresholding techniques, spatial maps of snow depth, snow cover and differences in snow depth (dHS) during ablation were generated in very high resolution as proxies for spatial SWE, spatial ablation rates and SCD. The results indicate that the initial distribution of snow depth was highly variable due to overwinter snow redistribution; thus, the subsequent distribution of dHS was also variable due to albedo, slope/aspect and other unaccountable differences. However, the initial distribution of snow depth was 5 times more variable than that of the subsequent dHS values, which varied by a factor of 2 between the north and south aspects. dHS patterns were somewhat spatially persistent over time but had an insubstantial impact on SCD curves, which were overwhelmingly governed by the initial distribution of snow depth. The reason for this is that only a weak spatial correlation developed between the initial snow depth and dHS. Previous research has shown that spatial correlations between SWE and ablation rates can strongly influence SCD curves. Reasons for the lack of a correlation in this study area were analysed and a generalisation to other regions was discussed. The following questions were posed: what is needed for a large spatial correlation between initial snow depth and dHS? When should snow depth and dHS be taken into account to
\end{abstract}

correctly model SCD? The findings of this study suggest that hydrological and atmospheric models need to incorporate realistic distributions of SWE, melt energy and cold content; therefore, they must account for realistic correlations (i.e. not too large or too small) between SWE and melt in order to accurately model SCD.

\section{Introduction}

The spatial variability of snow water equivalent (SWE) exerts an important control on catchment or grid-averaged snowmelt (Pomeroy et al., 1998; Liston, 1999). When focusing on complex terrain with only minor vegetation effects on SWE distribution, differences in precipitation, snow redistribution, melt energy and freezing levels lead to a spatially variable distribution of SWE (e.g. Clark et al., 2011). For modellers of snow-hydrological applications the question arises as to which of those processes need to be considered. It is well known that south-facing slopes receive more melt energy than north-facing slopes due to differences in solar radiation. At $50^{\circ} \mathrm{N}$ on 1 April, the differences are already $40 \%$ for a slightly inclined $10^{\circ}$ slope; however, these differences decrease as summer solstice approaches (Fig. 1, Gray and Male, 1981). It is also well known that SWE distribution at peak accumulation is highly variable in alpine terrain. Liston (2004) presented maps showing regional differences in the coefficients of variation $(\mathrm{CV})$ of snow depth. For alpine regions a $\mathrm{CV}$ of 0.85 is suggested. Both, the variability in melt energy and SWE influence snow-cover depletion. This can be visualised using snow-cover depletion curves, which are a function of snow-covered area (SCA) over time or grid- 


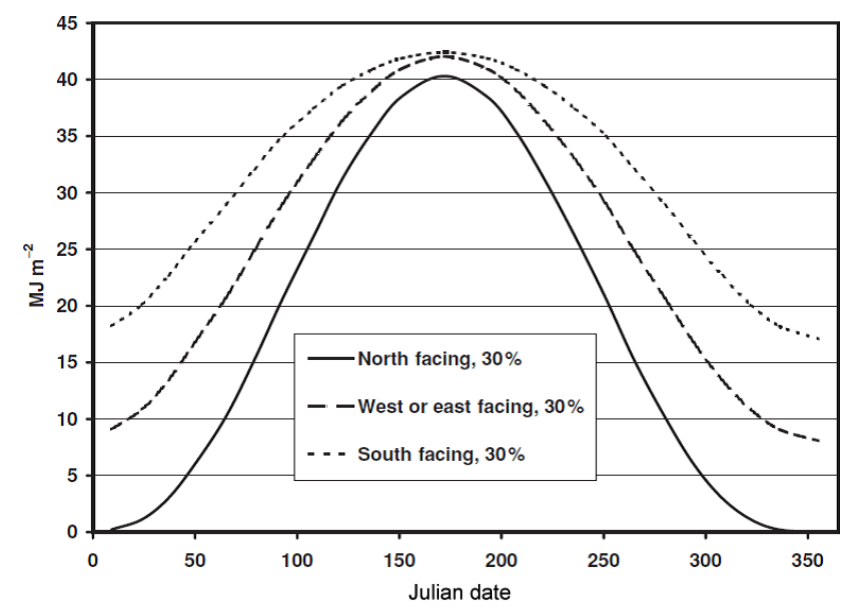

Figure 1. Extraterrestrial solar irradiance at $50^{\circ} \mathrm{N}$ for north-, southand east-/west-facing $30 \%$ slopes. Note the small differences as summer solstice is approached (after Gray and Male, 1981).

averaged SWE (e.g. Essery and Pomeroy, 2004; Clark et al., 2011). Using theoretical simulations, both studies illustrate how increasing melt rate and peak SWE variability change the rate of areal snow-cover depletion. From their theoretical illustrations (Figs. 3 and 4 in Clark et al., 2011), it is clear that in alpine regions with a large variability in melt rate and peak SWE, ignoring SWE rather than melt rate variability would be the greater modelling mistake. However, as Pomeroy et al. (2004) pointed out, the importance of melt variability on snow-cover depletion (SCD) increases if a spatial correlation between melt and SWE exists. This suggests that the question of relative contribution of spatially variable melt rates or snow redistribution on SCD in alpine terrain can be reduced to the question of whether such a correlation between melt and SWE exists and how large it is.

Besides theoretical considerations, there are a number of existing field and modelling studies on the relative importance of spatially variable melt or snow redistribution on SCD. There are studies that have found the temporal progression of snow-cover depletion (SCD) to be governed primarily by the variability caused by snow redistribution rather than the variability caused by melt rate differences (Shook and Gray, 1994; Luce et al., 1998; Anderton et al., 2004; Egli et al., 2012). Using spatial observations, these studies show that SCD can be modelled with statistics derived during peak accumulation. Luce et al. (1998) modelled snow-cover depletion with a spatially distributed energy balance model that integrated drifting snow redistribution based on an empirically derived drift factor. Ignoring this drift factor deteriorated model results, which suggests the relative importance of snow redistribution over melt variability. Grünewald et al. (2010) made indirect measurements of the spatial melt rate and SWE via snow depth (HS) and the change in HS (dHS) using terrestrial lidar and applying a few measured bulk densities to estimate SWE and abla- tion rates. They found that SWE and the melt rate were spatially uncorrelated over most of their ablation season, except for a correlation coefficient $(r)$ of -0.4 for one sub-period. They noted that the variability of SWE was much larger than the variability of melt rates. In the same study area over an additional winter season, Egli et al. (2012) calculated SCD curves that assumed correlations between HS and dHS; however, these curves deviated substantially from observations, suggesting that such correlations did not exist. Neither study examined why such correlations were absent.

In contrast, spatially varying melt rates - caused by differences in insolation due to aspect (Marks and Dozier, 1992), net solar irradiance due to albedo differences (Skiles et al., 2015), internal energy storage due to deep, cold snow (DeBeer and Pomeroy, 2010) and advected energy due to bare ground (Mott et al., 2011, 2013) can alter this pre-melt SWE distribution and, when correlated with SWE, result in substantial changes to SCD curves (Pomeroy et al., 2004; Essery and Pomeroy, 2004; DeBeer and Pomeroy, 2010). Pomeroy et al. (2003) took measurements of energy fluxes to snowpacks, using eddy correlation and slope-based radiometers, and snow ablation, using spatially distributed snow surveys, in a Yukon mountain valley in April; their study found that whilst ablation was proceeding rapidly on south-facing slopes where snow was initially shallow, snow accumulation was still occurring on north-facing slopes where a large drift had formed. In Yukon and the Canadian Rockies, subsequent studies have found melt variations to be important in controlling snow ablation and SCD (Pomeroy et al., 2003, 2004; Dornes et al., 2008a, b; DeBeer and Pomeroy, 2009, 2010). Pomeroy et al. (2004) reported that different spatial scales and landscape classes influence melt rates to be either positively or negatively correlated with pre-melt SWE throughout melt in a wide variety of cold region mountain environments. In a windswept alpine catchment subject to substantial snow redistribution, DeBeer and Pomeroy (2010) found that melt rate variations were important in the Canadian Rockies during early melt. Winstral and Marks (2014) found that modelled SWE and melt rates were correlated with an $r$ value of -0.66 in the mountains of southern Idaho. Such a large correlation between modelled melt and SWE would indicate that spatial melt differences are relevant to correctly model SCD in some regions. Dornes et al. (2008a, b) found that hydrological models and land surface schemes that did not consider slope and aspect impacts on melt as well as initial SWE could not be calibrated to produce realistic SCD curves or streamflow discharge hydrographs. Furthermore, they showed substantial interannual variability of SWE distributions and correlations with melt rate. Interannual differences of the interplay of SWE and melt variability will enhance the problem of correctly modelling SCD.

Regional differences, e.g. the complexity of the terrain and wind redistribution, will alter the dominance of SWE variability on SCD and may therefore partly explain the different findings of various studies. Not all cited studies fall into 
the highest CV category suggested by Liston (2004). Furthermore, in study regions with large elevation gradients, altitudinal melt energy differences as well as precipitation phase differences will play an important role in governing SCD (Blöschl and Kirnbauer, 1992; Elder et al., 1998).

From a practical modelling perspective, it is simpler to explicitly calculate melt energy differences in a model (Marks and Dozier, 1992) than to calculate snow redistribution mechanistically over complex terrain (Liston and Sturm, 1998; Mott et al., 2010; Fang et al., 2013; Musselman et al., 2015). Therefore, empirical modelling of SWE variability (Luce et al., 1999; Winstral and Marks, 2002; Liston, 2004; Essery and Pomeroy, 2004; Helbig et al., 2015) has been a preferred choice. As Essery and Pomeroy (2004) pointed out, it is relevant to also consider the spatial correlation between melt and SWE to correctly model SCD. One attempt in this direction is shown in DeBeer and Pomeroy (2010), who modelled this correlation based on the cold content of snow. High-resolution gridded model approaches with energy balance models include this effect as well, but only with a realistic SWE distribution can one also assume a realistic correlation with spatially modelled melt rates. Brauchli et al. (2017) extended the method of Luce et al. (1998) to a higher spatial resolution, i.e. scaling measured solid precipitation to observations using lidar data. Without discussing the effect of an improved correlation between modelled melt and SWE compared with standard methods of distributing precipitation, Brauchli et al. (2017) were able to improve modelled runoff for certain periods.

The present study aims to assess the influence of peak SWE variability, melt rate variability and particularly their spatial correlations on SCD in alpine terrain using highresolution distributed measurements rather than sparse manual sampling or relying on model results. The use of highresolution measurements is potentially important because the peak snow depth, and thus also peak SWE, is known to vary most substantially below the scale of tens of metres in alpine environments. The coarse-resolution manual probing of previous studies may have missed important spatial structures that may determine the results (Clark et al., 2011). Most studies on this topic have relied on modelled melt rates, even though there are substantial uncertainties in melt modelling over complex terrain. For instance, Mott et al. (2011) were only partly successful in the high-resolution modelling of alpine melt rate variations. Those studies that have used highresolution distributed snow depths, such as Egli et al. (2012), did not attempt to diagnose the variation of and correlation between SWE and melt rates.

\section{Data and methods}

\subsection{Site description}

A study region was chosen which showed substantial differences in aspect and slope to ensure spatial melt differences. At a nearby study site, DeBeer and Pomeroy (2010) found spatial melt rates to be important for snow-cover depletion, at least during early melt. Large drifts commonly form on south-facing slopes in this area (MacDonald et al., 2010; Musselman et al., 2015), suggesting a correlation between melt energy and SWE. The study area is located in the Canadian Rocky Mountains in southern Alberta, Canada. Figure 2a shows a topographic map of the study area, an alpine ridge in a northeast-southwest orientation. Gullies and small-scale aspect variations can be found in the slopes on both sides of the ridge. Extreme south and north aspects are underrepresented in the snow-covered terrain at the beginning of the study period (Fig. 2b). The snow-covered area is reasonably steep with two peaks in the slope distribution at 10 and $25^{\circ}$ (Fig. 2c). On both sides of the ridge the slope steepens to up to $40^{\circ}$. Vegetation played a role in snow deposition patterns, mainly in the lee of shrubs and clusters of small trees in krummholz with heights of up to $2 \mathrm{~m}$. Areas within these vegetation clusters were excluded from the study as vegetation degraded the digital surface models (DSMs) derived from unmanned aerial vehicle (UAV) structure-from-motion (SfM) photogrammetry (see Sect. 2.4). The included area only covered bare or sparsely vegetated ground so that vegetation effects could be excluded.

Two weather stations are located on the ridge: one on top of the ridge (Fortress Ridge - FRG) and one in a southfacing slope (Fortress Ridge South - FRS, Fig. 2a). The local Fortress Mountain Snow Laboratory within the regional Canadian Rockies Hydrological Observatory provided five more weather stations within less than $2 \mathrm{~km}$ of the ridge, which were used to interpret weather situations and for quality control.

\subsection{Unmanned aerial vehicle (UAV) data acquisition}

A "Sensefly eBee RTK" fixed wing UAV was used with a modified consumer-grade Canon ELPH compact RGB camera. As a base station a Leica GS15 differential GPS system communicated with the UAV to tag captured images with corrected geolocations. Additionally, ground control points were measured with this differential GPS system, which improved the quality of the digital surface models (DSMs) generated. For a more detailed description of the UAV and the UAV usage please refer to Harder et al. (2016). An area of $0.31 \mathrm{~km}^{2}(666 \mathrm{~m} \times 470 \mathrm{~m})$ was separated into two subareas due to battery restrictions on flight coverage (Fig. 2a, red rectangles). Each flight lasted approximately $20 \mathrm{~min}$. The flight altitude was $100 \mathrm{~m}$ over the ridgetop, which resulted 

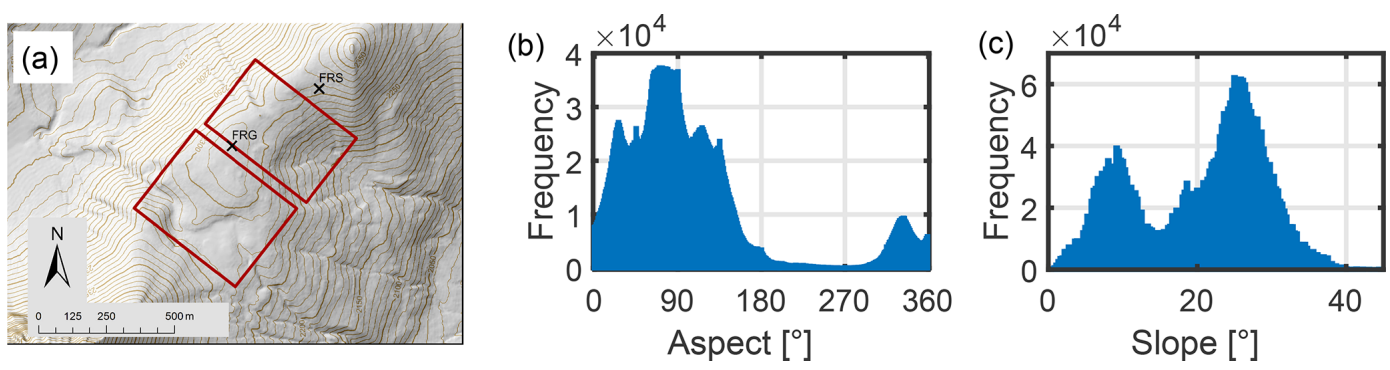

Figure 2. Topography of the study site: (a) an overview of the two areas of investigation (red rectangles) with the location of the two weather stations (black crosses) on the alpine Fortress Ridge, Alberta, Canada; (b) the aspect and (c) slope distribution of the snow-covered area on 27 May 2015 (at a spatial resolution of $10 \mathrm{~cm}, N>3 \times 10^{6}$.

in an approximate resolution (ground sampling distance) of less than $4 \mathrm{~cm}$. An $85 \%$ lateral overlap of the images and a $75 \%$ longitudinal overlap were chosen, as these values are suggested by the manufacturer for difficult terrain. Ideally, a total of four flights were carried out each sampling day, two for each subarea with perpendicular flight plans, which again follows the manufacturer's suggestion for complex terrain. Weather conditions and technical problems often only allowed for a part of this programme to be carried out. Wind speeds over $14 \mathrm{~m} \mathrm{~s}^{-1}$ or the occurrence of precipitation restricted flying, while camera malfunctions or connection issues with the Leica GPS base station were the most typical technical limitations. In total, the UAV was flown over snow from 15 May to 24 June 2015 on 8 different days with substantial depth differences, and four flights were carried out over bare ground on 24 July 2015. However, as stated Sect. 3.2, we had to restrict analysis to two melt periods.

\subsection{Accuracy evaluation and manual measurements}

The accuracy assessment of this rather new method of determining snow depth was given a high priority and is described in detail by Harder et al. (2016) for this environment and others. In short, 100 differential GPS measurements on bare ground were taken. Approximately $60 \%$ of the area was bare at the beginning of the study period which allowed for the distribution of GPS ground measurements over a large part of the study area (Fig. 3a) and thus widespread detection of any general misalignment of DSMs or local tilts. These points could be used for all available flights. Differential GPS measurements were also taken at the snow surface on the day of the specific flights, but technical problems often only allowed limited additional time for these surveys. For most of the days up to 20 differential GPS measurements on snow could be taken. At these GPS measurement points, snow depth was also manually measured, whereas snow density was measured at approximately one-third of these points. Density measurements were not sufficient to confidently calculate SWE from snow depth into SWE and ablation rates from differences in snow depth. As such, HS and dHS are analysed and interpreted as proxies for SWE and melt in the text. As redistribution and compaction of snow were not relevant processes for this time period (late in the ablation season), dHS can serve as a reasonable proxy for melt.

Harder et al. (2016) described errors and accuracies of the UAV measurements in detail. In short, from 100 measurements on bare ground, the root-mean-square errors of the bare ground surface elevation ranged between 4 and $15 \mathrm{~cm}$ with a mean of less than $9 \mathrm{~cm}$. Over snow with fewer measurements an increase in these error measures could not be detected. A signal-to-noise ratio (SNR) was used to ensure that the signal of the UAV was sufficiently larger than the error, defined as the mean of the signal divided by the standard deviation of the error. The potential impact of this error on the results presented is discussed in Sect. 3.2.

\subsection{Spatial data generation}

Digital surface models (DSMs) and orthomosaics were created using SfM techniques (Westoby et al., 2012) with the Postflight Terra 3-D software, which was provided with the UAV. Default settings likely resulted in overexposed pixels, which created erroneous points in the point cloud over snow that appeared several metres above the real snow surface. This issue could be partly solved with a semi-global matching option within the software, which reduced the number of affected areas. Remaining areas with errors were manually excluded (Harder et al., 2016). DSMs and orthomosaics were resampled to a common grid and a resolution of $10 \mathrm{~cm}$, which substantially increased the speed of subsequent data analysis.

Subtracting DSMs provided both snow depth (HS) and differences in snow depth (dHS). dHS was scaled by the time interval between observations for the comparison of varying observation periods. Snow-covered area (SCA) was defined using individual thresholds in RGB values for different flights utilising the orthomosaics. Manual adjustment was needed to ensure that very dark snow was classified correctly (see e.g. Fig. 3b). HS was masked by the SCA on the date of the flight, whilst dHS was masked by the SCA on the dates of the first and subsequent flight. Figure $3 \mathrm{c}$ and d show examples of the HS and dHS maps of a part of the study area. 

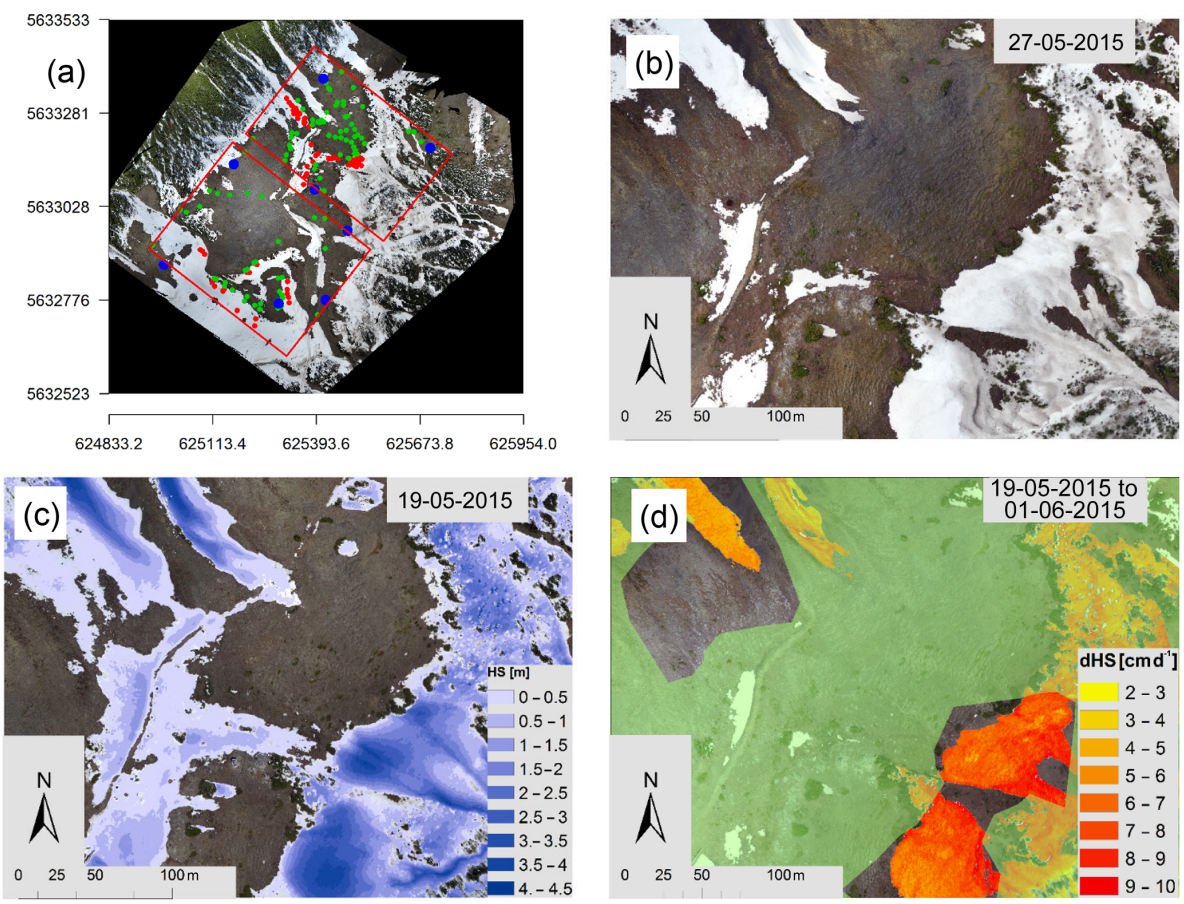

Figure 3. UAV photogrammetric data for the study site. (a) Orthomosaic from images captured on 22 May 2015, showing the two N and $\mathrm{S}$ areas of investigation (red polygons); the points indicate the locations of manual snow depth and differential GPS measurements over snow (red) and bare ground (green). The coordinates shown are in UTM zone 11N. Panels (b), (c) and (d) are enlargements of part of the study area showing evidence of dust on snow, snow depth (HS) on 19 May 2015 and differences in snow depth (dHS) between that date and 1 June, respectively. The green colour in indicates areas excluded from the analysis due to human impacts on the snow or substantive vegetation.

Several areas such as ski lifts, snow cat tracks and erroneous points (as mentioned above) were excluded from the analysis. Furthermore, large errors were detected in areas close to vegetation, which were manually excluded. The marked green area in Fig. 3d indicates the excluded area for this part of the study region.

To explain the observed differences in snow depth, several topographical variables were created using the DSMs. "Deviation from north" and "slope" were calculated at a $1 \mathrm{~m}$ resolution to exclude small-scale noise of the DSMs. "Solar irradiance" was calculated at a $1 \mathrm{~m}$ resolution for each flight day using the "Area Solar Radiation" function in ArcGIS. To account for albedo differences the "brightness" of the orthomosaic pixels was extracted at a $10 \mathrm{~cm}$ resolution. The blue value was chosen as it was least affected by unwanted illumination differences due aspect variations. Brightness and solar irradiance are temporal averages based on the first and the last flight and, if available, flights within the periods.

\subsection{Data analysis}

To diagnose reasons for spatial differences in snow depth change (dHS), Pearson correlation coefficients were calculated using several potential explanatory variables such as slope, deviation from north, solar irradiance, brightness, current snow depth (HS) and snow depth at the beginning of the study period $\left(\mathrm{HS}_{0}\right)$. Scatter plots were also visually inspected to detect reasons for strong or weak correlations or non-linear dependencies. The scatter plots were too dense to visually interpret due to the high resolution; therefore, instead of plotting point pairs, the density of point pairs in a limited area of the plot was visualised (e.g. in Fig. 5a).

Spatial dependencies of the spatial structure of dHS and its correlation with explanatory variables were analysed using variograms and correlograms. Variograms were calculated with

$\hat{\gamma}_{x}(h)=\frac{1}{2|N(h)|} \sum_{(i, j) \in N(h)}\left(x_{j}-x_{i}\right)^{2}$,

for point pairs $x_{i}$ and $x_{j}$ in lag distance class $N(h)$ (e.g. Webster and Oliver, 2007). Correlations between two variables, $x$ and $y$, at a certain lag distance, $h$, were calculated with the cross-variogram as an estimator of the covariance (Webster and Oliver, 2007).

$\hat{\gamma}_{x y}(h)=\frac{1}{2|N(h)|} \sum_{(i, j) \in N(h)}\left(x_{j}-x_{i}\right)\left(y_{j}-y_{i}\right)$

This covariance was scaled with estimators of the variance $\hat{\gamma}_{x}$ (Eq. 1) using

$\rho_{x y}(h)=\frac{\hat{\gamma}_{x y}(h)^{2}}{\hat{\gamma}_{x}(h) \hat{\gamma}_{y}(h)}$, 
in order to obtain a correlation measure (Webster and Oliver, 2007). Variograms and correlograms were only calculated with a random subset of $10 \%$ of the available data points to save computational resources. The smallest number of observations was $N>5 \times 10^{4}$, which was large enough to obtain consistent variograms and correlograms with different randomly chosen subsets.

\section{Results and discussion}

\subsection{Overview and meteorology}

Fortress Ridge is well exposed to the wind, with peak hourly wind speeds of over $20 \mathrm{~m} \mathrm{~s}^{-1}$ and a mean of $4.6 \mathrm{~m} \mathrm{~s}^{-1}$ over the winter 2014/2015 at the FRG station. Two dominant wind directions can be identified, west-southwest and eastsoutheast, the latter is approximately perpendicular to the ridge. The wind direction parallel to the ridge is associated with the highest wind speeds. During precipitation and highwind events both directions are frequent. During late melt in 2015, wind speeds were substantially lower with a higher frequency of very calm days, which provided more frequent suitable flying conditions for the UAV.

Due to high wind speeds, large parts of the ridge were snow-free during most of the exceptionally warm, dry winter season. After a large late November 2014 snow storm, the FRG station rarely documented snow on the ground and the shallow snowpacks that did form were regularly eroded by wind within a few days. The snow-covered area (SCA) reached the seasonal maximum in late November after the above-mentioned substantial snowfall $(80 \mathrm{~mm})$ with light winds, and then dropped dramatically due to subsequent wind redistribution from blowing snow storms. When aerial measurements began on 19 May 2015, the SCA was slightly below its typical winter value as spring ablation was under way. Without excluding any areas (see Sect. 2.4), the SCA was approximately 0.45 in both subareas (Fig. 3a).

Dust-on-snow was an obvious feature in late winter and the beginning of the melt season (Fig. 3b). It had not been observed to such extent in over a decade of observations in the region. This dust was locally eroded from the fine frost-shattered and saltation-pulverised shale particles at the ridgetop and was transported by wind to adjacent lee slopes and into gullies, similarly to wind-transported snow. Hence, dust was preferentially deposited to snow drifts. Subsequent snow accumulation and melt processes led to a dust-on-snow pattern of high small-scale variability. The lower albedo from dust deposition may have influenced snowmelt energetics, but its high variability is different from the large-scale, areally uniform dust deposition reported by Painter et al. (2010) where the dust source is in upwind arid zones and very fine aerosols are evenly deposited on snow.

Blowing snow transport and redistribution under high wind speed conditions also caused a highly variable snow depth (Fig. 3c) as is expected in the region (Fang et al., 2013; Pomeroy et al., 2016). Snow was redistributed to the southeast-facing slopes of the ridge and also in gullies on the northwest-facing slopes, which are perpendicular to the ridge. Areas of bare ground and very deep snow ( $>4 \mathrm{~m}$ ) were only separated by a few metres. This high variability of snow depth at scales of from a few to tens of metres is a typical feature of wind-swept alpine snow covers (e.g. Pomeroy and Gray, 1995, 22-27; Deems et al., 2006; Trujillo et al., 2007; Schirmer et al., 2011; Schirmer and Lehning, 2011). There is no avalanching redistribution of snow in the study domain.

An example of reductions in snow depth (dHS) due to ablation over a period of $13 \mathrm{~d}$ is shown in Fig. 3d. At first glance, differences between aspects are obvious, as is the smaller-scale impact of albedo variations (cf. Fig. 3b). The driving forces of differences in ablation inferred from the observed differences in depth change will be examined in Sect. 3.3.

The study covered the late melt period, when the highest ablation rates occurred. A peak SWE of $500 \mathrm{~mm}$ was measured with a weighing snow lysimeter (Sommer "snow scale") in a nearby forest clearing on 20 April 2015. By the start of the study period on 19 May, SWE had gradually decreased to $300 \mathrm{~mm}$, often interrupted by snowfall. During the study period after 19 May, no significant $(>3 \mathrm{~cm})$ snowfall was observed. The much higher ablation rates compared with the previous weeks caused the snow to disappear at this station on 30 May. A very similar development could be observed at two other stations using snow depth sensors within the Fortress Mountain Snow Observatory, including the FRS station (cf. Fig. 2a). On 30 May a SCA of 0.2 was measured from the UAV over the whole flight domain. Considering a typical pre-melt SCA of approximately 0.45 , the presence of a significant SCA illustrates the value of spatially distributed measurements of snow ablation and cover, when all seven meteorological stations in the $\sim 3 \mathrm{~km}^{2}$ region were snowfree.

A meteorological overview during the study period is given in Fig. 4 at the FRG station (cf. Fig. 2a). Measurements of incoming shortwave radiation and air temperatures are shown in Fig. 4a, and the resulting modelled outcome with the Cold Regions Hydrological Model (CRHM) using SNOBAL as the melt module (cf. Fang et al., 2013) for a flat-field simulation are shown in Fig. 4b. Although the FRG station was snow-free, CRHM was initialised with a hypothetical SWE amount of $800 \mathrm{~mm}$ in order to represent deeper nearby snow patches. Energy fluxes were summed and scaled for comparison over the indicated dates with UAV flights. The energy balance was dominated by inputs of net shortwave radiation. Modelled melt accelerated around 8 June when high incoming shortwave radiation was accompanied by smaller longwave radiation losses and larger sensible heat fluxes driven by air temperatures often in excess of $10^{\circ} \mathrm{C}$. 

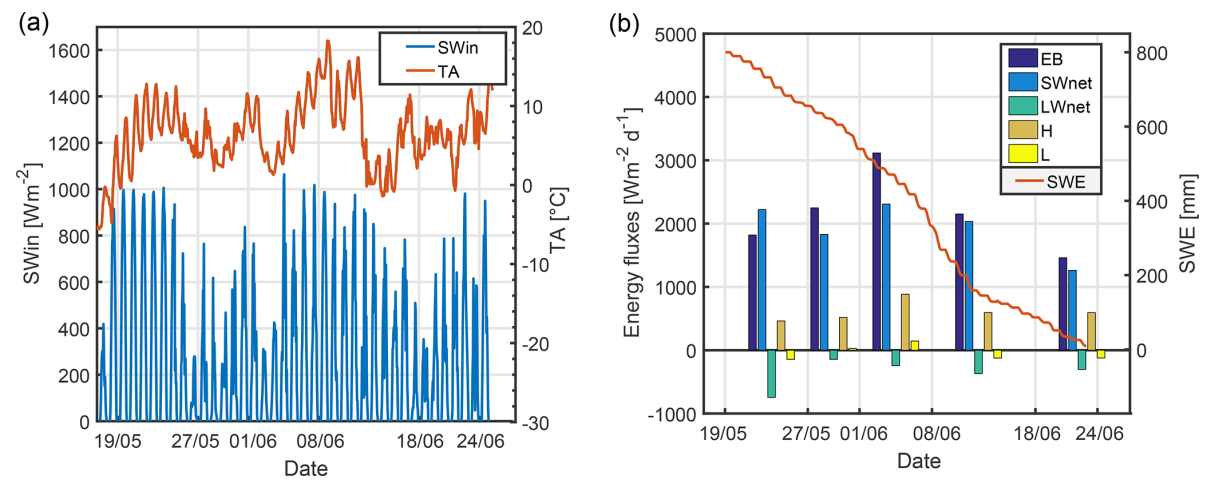

Figure 4. Measured (a) and modelled (b) values at the FRG station, showing energy fluxes per day for periods between UAV flights as modelled by CRHM. EB is the total energy flux; $\mathrm{SW}_{\text {net }}$ and $\mathrm{LW}_{\text {net }}$ are net shortwave and longwave radiation respectively; $H$ and $L$ are sensible and latent heat fluxes, respectively. Heat advected by rain and ground heat flux that only have small contributions are not shown.

\subsection{Selection of melt periods}

Melt periods were chosen to include sufficient ablation such that the dHS signal exceeded the measurement error from the UAV and data processing. A signal-to-noise ratio (SNR) was used, which relates the mean dHS to the typical standard deviation error (SD); Harder et al. (2016) found this value to be $6.2 \mathrm{~cm}$ for surfaces measured with the UAV. As two surface measurements are needed to achieve a dHS map, this $\mathrm{SD}$ value was doubled. For a $\mathrm{SNR} \geq 4$, the signal is assumed to be large enough to avoid mistaking it for a fluctuation in noise (Rose, 1973). Applying this criterion, mean dHS had to be larger than $\sim 0.5 \mathrm{~m}$. Given the availability of suitable flights in both subregions, this permitted two time periods for analysis; $P_{1}$ from 19 May to 1 June 2015, and $P_{2}$ from 1 to 24 June 2015.

\subsection{Factors influencing spatial differences in dHS}

Table 1 shows the Pearson correlation coefficient for the above-mentioned melt periods and different subareas. This univariate analysis clearly shows two driving factors for the earlier melt period $\left(P_{1}\right)$ - albedo and solar radiation differences - which are respectively expressed using brightness and either deviation from north or solar irradiance. The sign of the correlations is mainly as expected: more southerly and darker pixels showed larger dHS values. Exceptions (e.g. during $P_{2}$ in the southern subarea) may be explained by observable differences between a few remaining snow patches with different albedo values, slopes, snow depths and sky view factors. Energy contributions from longwave radiation (DeBeer and Pomeroy, 2009) or altered turbulent heat fluxes because of cold air pooling (Mott et al., 2011, 2016) may override an obvious relationship with solar radiation. Furthermore, faster settling rather than melt of deeper snow is possible, although the snowpack was quite ripe.

In the first period $\left(P_{1}\right)$ brightness had a large effect in the northern subarea $(r=-0.66)$. Figure 5 a visualises this rela-
Table 1. Pearson correlations coefficient $(r)$ between dHS and the explanatory variables. $P_{1}$ is from 19 May to 1 June and $P_{2}$ is from 1 to 24 June. $n$ is number of observations.

\begin{tabular}{llrrrrr}
\hline Period & Area & Brightness & $\begin{array}{r}\text { Degrees } \\
\text { from } \\
\text { north }\end{array}$ & $\begin{array}{r}\text { Solar } \\
\text { irradiance }\end{array}$ & $\mathrm{HS}_{0}$ & $n$ \\
\hline$P_{1}$ & All & -0.47 & 0.56 & 0.39 & -0.12 & 3245837 \\
$P_{2}$ & All & -0.59 & 0.30 & 0.01 & 0.33 & 706344 \\
$P_{1}$ & $\mathrm{~N}$ & -0.66 & 0.57 & 0.57 & -0.24 & 1410768 \\
$P_{2}$ & $\mathrm{~N}$ & 0.03 & 0.84 & 0.84 & 0.03 & 183822 \\
$P_{1}$ & $\mathrm{~S}$ & -0.43 & 0.39 & 0.33 & 0.01 & 1835069 \\
$P_{2}$ & $\mathrm{~S}$ & -0.68 & -0.21 & -0.61 & 0.30 & 522522 \\
\hline
\end{tabular}

tionship between dark snow and dHS. The high scatter especially for brighter snow pixels can be partly explained by radiation differences. For the same period and area, solar irradiance and deviation from north had a correlation of 0.57. Figure $5 \mathrm{~b}$ illustrates the dependence on solar irradiance but for white pixels only (approximately $50 \%$ of the observations). A clear dependence is visible with a correlation coefficient of 0.66. Radiation effects were more substantial during $P_{2}$ in this northern subarea with an $r$ value of 0.84 for both solar irradiance and deviation from north. This may be explained due to less scatter produced by albedo differences in this period $(r=0.03)$. Darker parts of the snow cover melted out by the end of this period.

The correlations of dHS with brightness, deviation from north and solar irradiance were often strong. dHS increased from 5 to $7 \mathrm{~cm} \mathrm{~d}^{-1}$ (an almost $60 \%$ increase) as aspect shifted approximately $115^{\circ}$ from north to south or snow changed from clean to dusty (cf. Fig. 5b). This shows the importance of spatial variation in net solar irradiance on melt energetics - as exemplified by the modelled energy budget shown in Fig. 4b. The impact of dust on albedo and slope on solar irradiance is well established in snow literature and so this is expected.

A more interesting finding here is that dHS was not correlated with initial $\mathrm{HS}_{0}$ (Fig. 5c, Table 1), as has been ob- 

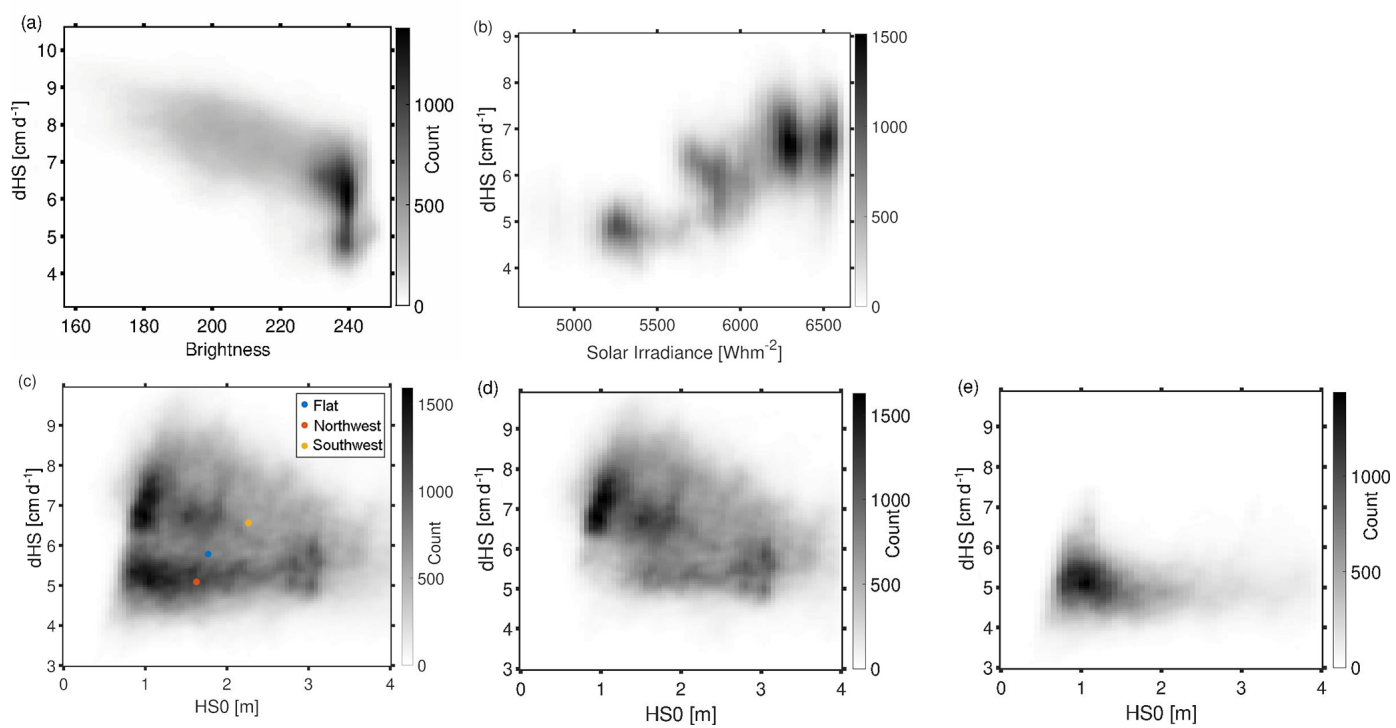

Figure 5. Scatter plots of (a) snow brightness and (b) solar irradiance versus differences in snow depth (dHS) for the northern subarea during $P_{1}$. Darker tones indicate a higher density of points. In panel (b) only bright snow pixels are used (brightness $>230$ ); scatter plots (c, d) show the dependence of $\mathrm{dHS}_{\text {and }} \mathrm{HS}_{0}$ for the whole area with mean values (coloured points) for either side of the ridge and additionally flat pixels (c), and only on the northwestern (d) and southeastern part of the ridge (e).

served in other cold region mountain studies in Canada such as DeBeer and Pomeroy (2009, 2010), Pomeroy et al. (2003, 2004) and Dornes et al. (2008a, b). A lack of covariance between $\mathrm{HS}_{0}$ and $\mathrm{dHS}$ in late melt has important implications for SCD curves (Pomeroy et al., 2001), which will be highlighted in Sect. 3.5. Figure 5c shows the areal mean values for $\mathrm{HS}_{0}$ and $\mathrm{dHS}$ for flat areas (slope $<5^{\circ}$ ) and areas on both sides of the ridge (threshold aspect is $235^{\circ}$, slope $\geq 5^{\circ}$ ). The hypothesis for this study period was that large drifts on south-facing parts of the ridge cause a correlation between melt energy and SWE. Indeed, the southeast part showed larger $\mathrm{HS}_{0}$ and $\mathrm{dHS}$ values than the flat or the northwest part of the study area. This suggests a correlation between $\mathrm{HS}_{0}$ and dHS when analysing areal mean values, which was not apparent when analysing all pixels. More importantly, on the southeastern face a mild negative correlation of -0.35 developed (Fig. 5d), which may be explained by a remaining cold content in deep drifts. This negative correlation is not apparent for smaller dHS values on the northwest part of the ridge (Fig. 5e). The lack of a correlation in the point cloud in Fig. $5 \mathrm{c}$ can be interpreted as a compensation between the positive correlation driven by melt energy and the negative correlation from cold content.

To aid in analysing the reasons for the lack of correlations between HS and dHS in this study area, one can formulate some prerequisites for large spatial correlations in general. For instance, cold content has the potential to establish a negative correlation as deeper snowpacks take longer to warm up to $0{ }^{\circ} \mathrm{C}$; therefore, shallower snowpacks start melting earlier. This results in greater melt for shallower snowpacks. The spatial distribution of SWE and melt energy on slopes may result in negative or positive correlations, which depend on whether deep drifts are found on north-facing or southfacing slopes. For a large correlation between HS and dHS, either snow redistribution to slopes or deep snow cold content processes needs to be present and need to not counteract each other. In such cases, the sign of the correlation driven by the spatial distribution of SWE melt energy must be negative (drifts on north-facing slopes) and hence similar to the negative correlation driven by greater cold content in deeper snow. Remote sensing techniques can determine where deep drifts occur on north-facing slopes (Wayand et al., 2018; Painter et al., 2016), and these are quite prevalent in many regions. DeBeer and Pomeroy (2010) showed that spatial variation in cold content was large only in early melt and was unimportant to SCD later in the melt season when isothermal snowpacks predominate.

Given these scenarios, some guidelines for modelling areal SCD can be provided. Models must be able to represent realistic correlations between SWE and melt in order to model the effect of this correlation on SCD (Essery and Pomeroy, 2004). Potential pitfalls are incomplete modelling representations that might neglect a governing process. To capture the spatial correlations, models need to include snow redistribution, internal snowpack energetics and melt rate variability on slopes at fairly fine scales $(<100 \mathrm{~m})$ in complex terrain. Semi-distributed models with homogenous snow distribution over large areas or distributed models that neglect blowing snow redistribution may misrepresent spatial correlations of SWE and melt.

Another reason for models misrepresenting spatial correlations between $\mathrm{HS}_{0}$ and dHS is discussed in Sect. 3.6, in 
Table 2. The mean, standard deviation (SD) and coefficient of variation (CV) for snow depth (HS) and snow depth change (dHS) for different periods and areas. $P_{1}$ was from 19 May to 1 June 2015 and $P_{2}$ was from 1 June to 24 June 2015 . Values are only given for snow-covered areas. Values for HS are given for the start date of the period. Values for dHS are given for the area that was snow covered at the end of the melt period.

\begin{tabular}{llccccccc}
\hline \multirow{2}{*}{ Period } & Area & \multicolumn{3}{c}{ HS $(\mathrm{m})$} & & \multicolumn{3}{c}{$\mathrm{dHS}\left(\mathrm{cm} \mathrm{d}^{-1}\right)$} \\
\cline { 3 - 4 } \cline { 7 - 9 } & & Mean & SD & CV & & Mean & SD & CV \\
\hline$P_{1}$ & All & 1.26 & 1.16 & 0.92 & & 6.22 & 1.22 & 0.20 \\
$P_{2}$ & All & 1.33 & 1.13 & 0.85 & & 7.57 & 1.19 & 0.16 \\
$P_{1}$ & $\mathrm{~N}$ & 1.28 & 0.93 & 0.73 & & 6.86 & 1.22 & 0.18 \\
$P_{2}$ & $\mathrm{~N}$ & 0.98 & 0.73 & 0.74 & & 6.76 & 1.35 & 0.20 \\
$P_{1}$ & $\mathrm{~S}$ & 1.25 & 1.27 & 1.01 & & 5.72 & 0.97 & 0.17 \\
$P_{2}$ & $\mathrm{~S}$ & 1.54 & 1.27 & 0.83 & & 7.86 & 0.98 & 0.12 \\
\hline
\end{tabular}

which the mismatch of scales of dHS and $\mathrm{HS}_{0}$ patterns is discussed.

\subsection{Variability of dHS in relation to $\mathrm{HS}_{\mathbf{0}}$ and temporal persistence}

Table 2 shows the mean, standard deviation and CV values of HS and dHS in different periods and subareas. Throughout the melt season $\mathrm{CV}$ values of dHS were about 5 times smaller than those of HS. At the start of the study period, the variability of dHS was smaller than that of HS by a factor of 3.7 to 6.7 .

For the whole area only, a weak temporal correlation $(r=$ 0.36 ) was found in a pixel-by-pixel analysis between ablation patterns over the two long periods $-P_{1}$ and $P_{2}$. Larger correlations were found for the northern subarea $(r=0.60)$. Ablation patterns in certain sub-periods with similar weather conditions were correlated with each other. For instance, ablation patterns in the cool and cloudy period between 5 May and 1 June were correlated with two other rather cloudy subperiods at the end of the study period with respective $r$ values of 0.49 and 0.64 , and with the later combined period $P_{2}$ $(r=0.70)$. Further investigation on how these correlations responded to weather was not possible given the reduced signal-to-noise ratio for shorter time periods and the inclusion of several weather types over longer periods.

\subsection{Depletion curves}

Maximum differences in dHS of up to $100 \%$ were measured (Sect. 3.3) and were spatially persistent, especially in the northern subarea. Similarly to Pomeroy et al. (2001) and Egli et al. (2012) the impact of spatial dHS on snow-cover depletion were analysed using the following scenarios:

1. Variable $H S_{0} /$ uniform $d H S$. This scenario started with the measured distribution of HS at the beginning of the study period $\left(\mathrm{HS}_{0}\right)$, and a spatially uniform dHS value was applied for each pixel. This value was determined using the observed mean ablation values shown in Table 3. Each pixel was reduced by this mean value and any negative values in HS were set to zero. SCA was defined as the ratio of the number of grid points with $\mathrm{HS}>0$ to all pixels.

2. Uniform $H S_{0} /$ variable $d H S$. In this scenario, the mean initial snow depth, as shown in Table 3, was uniformly distributed over the whole snow-covered area. Spatially variable dHS values as measured with the UAV were applied to each pixel. To obtain the exact melt-out time this scenario was calculated daily using a temporally constant dHS value between flights. No exact dHS amounts were available for pixels that melted out between flights. For those pixels, the mean areal dHS value was applied. The general shape of SCD curves was obtained when this scenario was also calculated at the time resolution of the UAV flights.

3. Uniform $H S_{0}$ /uniform $d H S$. This scenario is similar to scenario 2 , but a spatially uniform dHS value was applied to each pixel, each of which had a uniform $\mathrm{HS}_{0}$. This scenario was also calculated at a daily resolution.

In all scenarios, SCA was set to one for the area that was snow-covered at the start of the study period. Figure 6 shows mean HS ablation and SCD curves for the whole area and the northern subarea (Fig. 6a,b), for which more flights are available. Differences between measured development and the first scenario of uniform $\mathrm{dHS}$ and variable $\mathrm{HS}_{0}$ were not large. However, a large difference between measurements and the second and third scenarios with uniform $\mathrm{HS}_{0}$ and either variable or uniform dHS is obvious. Areal dHS in those scenarios was overestimated before modelled melt-out because of the overestimation of SCA. Later, areal dHS was underestimated (or zero) as most or all snow disappeared too early. This is particularly important when the aim is to model late rain-on-snow events in hydrological models (Pomeroy et al., 2016). These results indicate that it is possible to not represent the spatial melt variability in late melt and still simulate a realistic SCD curve, whereas this is not possible if the spatial variability of $\mathrm{HS}_{0}$ is not represented. This main feature is consistent with Egli et al. (2012).

The main reason why the observed dHS differences, which were substantial and partly persistent, did not influence SCD curves can be found in the small to negligible spatial correlation between dHS and $\mathrm{HS}_{0}$ (cf. Sect. 3.3 and Table 1). Large correlations substantially influence SCD: negative correlations accelerate SCD at the beginning of melt and delay it in late melt, lengthening the snowmelt season, whereas the opposite is seen for positive correlations (Essery and Pomeroy, 2004).

Where correlation is insignificant, spatial melt differences can be quite large without affecting SCD curves. In this case, spatially variable melt can be viewed as a nearly random pro- 
(a)

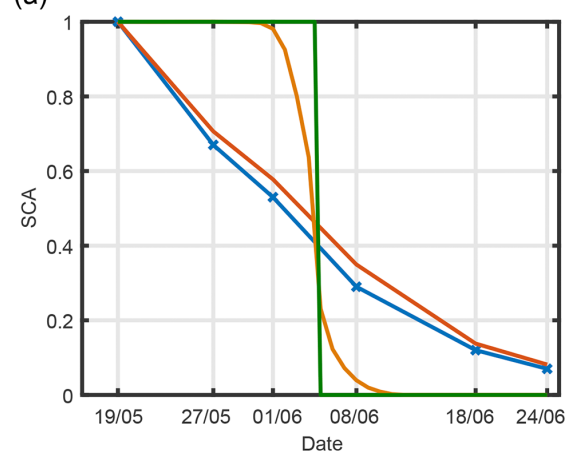

(c)

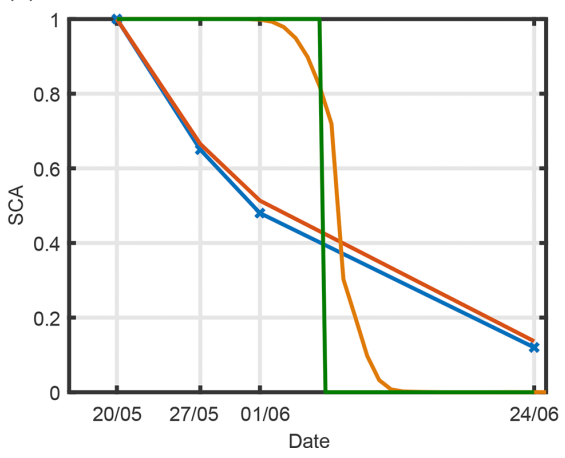

(b)

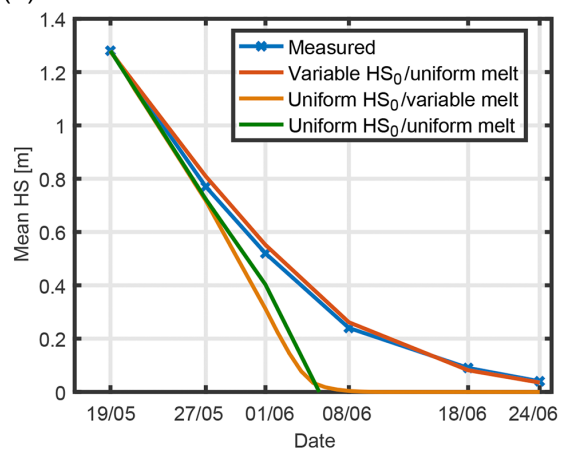

(d)

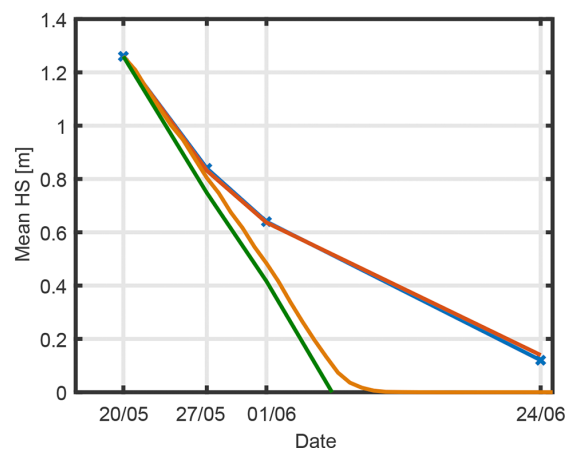

Figure 6. SCD and mean HS ablation for subarea N (a, b) and the total area (c, d): blue represents measured values, red represents modelled values initialised with measured HS distribution on 19 May and uniform melt, and green represents modelled values initialised with uniform snow depth distribution and uniform melt.

cess - it introduces noise into the lognormal frequency distribution of HS, but does not affect the emergent behaviour of the SCD curve. Here, with a much larger variability of $\mathrm{HS}_{0}$ compared with dHS (see Sect. 3.4) and only small spatial correlations between them (see Table 1), $\mathrm{HS}_{0}$ controls the SCD.

\subsection{Scale dependencies of dHS}

Figures 7 and 8 show how the variance of dHS, the variance of explanatory variables and correlations thereof develop with the larger lag distance between point pairs (variograms and correlograms, Eqs. 1-3). This gives further insights into the driving factors of ablation and why a correlation between $\mathrm{dHS}$ and initial $\mathrm{HS}_{0}$ was weak in this study area during late melt.

Figure 7a, the variogram of dHS, shows that the variance increased over two distinct length scales, one less than $50 \mathrm{~m}$ and one greater than $200 \mathrm{~m}$. This implies that the driving processes that generate variance for $\mathrm{dHS}$ need to be investigated at these two scales. In Sect. 3.3, a strong correlation was found between dHS and brightness and solar irradiance, although only weak correlations were found between these variables and $\mathrm{HS}_{0}$. Therefore, these variables were analysed with variograms and correlograms.
The variogram of brightness, shown in Fig. 7b, only indicates a variance increase at small lag distances of less than $50 \mathrm{~m}$. This is consistent with the visual impression of a smallscale variability of albedo shown in Fig. 3b. The correlogram, shown in Fig. 7c, reveals a strong correlation between brightness and dHS at these small scales $\left(\rho_{x y} \approx-0.6\right.$ at a $50 \mathrm{~m} \mathrm{lag}$ distance). This demonstrates that albedo was largely responsible for the small-scale dHS variability observed in Fig. 7a.

Figure 8a shows the variogram of solar irradiance. A small increase for length scales less than $100 \mathrm{~m}$ suggests radiation and aspect differences at those scales (within-slope variations), but the largest increase can be observed at lag distances longer than $200 \mathrm{~m}$. This scale represents slopes on both sides of the ridge and coincides with the larger scale of dHS variance. Indeed, the correlogram (Fig. 8b) confirms that the strongest correlation with dHS ( $\left.\rho_{x y}=0.4\right)$ was achieved at these larger distances.

The same analysis for initial snow depth $\left(\mathrm{HS}_{0}\right)$ can be seen in Fig. 8c and d. Most of the variance for snow depth is at length scales of less than $100 \mathrm{~m}$. The periodic behaviour shown beyond that scale may be due to the patchy snow cover which has long snow-free patches. No substantive correlation with dHS is observable on any scale (Fig. 8d). 
(a)

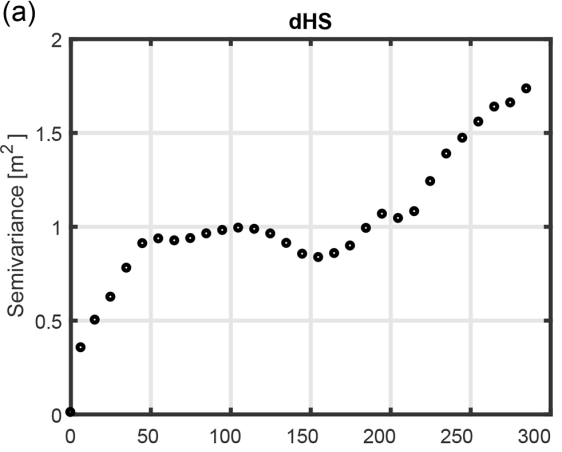

(c)

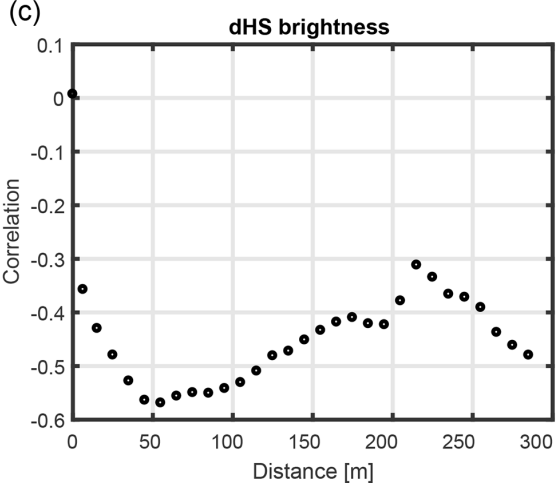

(b)

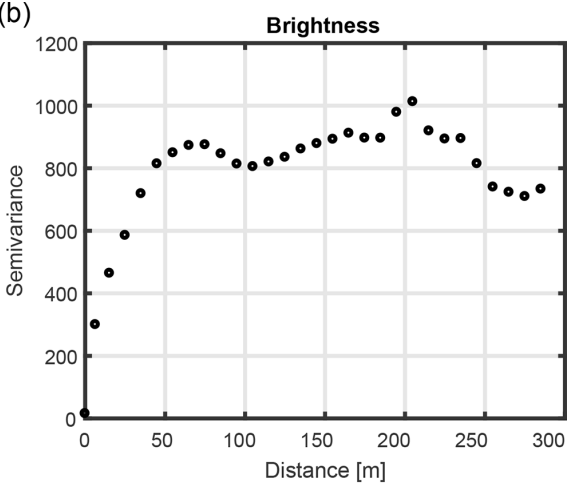

Figure 7. Variograms and correlogram for dHS and brightness.

This analysis offers further explanation of why dHS and $\mathrm{HS}_{0}$ were not spatially correlated in these observations. dHS variance was related to large-scale aspect changes on both slopes and medium-scale albedo change, whereas snow depth was variable mainly at much smaller scales. This scale mismatch leads to a larger scatter between $\mathrm{dHS}$ and $\mathrm{HS}_{0}$ values and, thus, prevented a substantive spatial correlation.

Two processes were previously discussed and described in Fig. 5c that could drive compensating correlations between $\mathrm{HS}_{0}$ and dHS: cold content and melt energy. Cold content likely acts on a similar scale to $\mathrm{HS}_{0}$, as it mainly depends on snow depth. As shown in Fig. 5d and e, a negative correlation driven by cold content is not uniformly present. Melt energy differences, i.e. differences in net shortwave radiation, turbulent fluxes and net longwave radiation, are not directly dependent on snow depth, but need to spatially coincide by chance (e.g. by direction of redistribution). By acknowledging that solar irradiance is a simple proxy of melt energy, spatial coincidences between accumulation and melt energy are only present over larger distances (Fig. 8b). The large scatter between $\mathrm{HS}_{0}$ and dHS results from the observation that most of the variance of $\mathrm{HS}_{0}$ occurs at much smaller scales (Fig. 8c). Figure 8d illustrates variability in the compensating correlations. At small scales (below $50 \mathrm{~m}$ ), the differences in solar irradiance are small and the cold content is responsible for a slight negative correlation between $\mathrm{HS}_{0}$ and dHS. This is counteracted by solar irradiance up to a distance of $250 \mathrm{~m}$ (cf. Fig. 8a).

There needs to be a match in scaling behaviour between SWE and melt rate for these variables to develop spatial correlations. Assuming melt is primarily driven by aspect and slope differences as in the proxy solar irradiance, SWE must vary on similar scales for a correlation to develop. This may be achieved if SWE varies primarily over larger scales, e.g. in a simple topography of a ridge without gullies and with one predominant wind direction during blowing snow, in which one slope face has much larger SWE values than the other. This may also be achieved if solar irradiance acts on a smaller scale, similar to $\mathrm{HS}_{0}$. This might be possible in highly complex terrain in which most slope/aspect differences can be found on scales below $100 \mathrm{~m}$, but this does not correspond to the "ridge" at our study site.

\section{Conclusions and outlook}

The aim of this study was to determine factors which influence areal snow ablation patterns in alpine terrain using spatially intensive observation. The dependence of snow accumulation and topographic variables on spatial melt rates were analysed for an alpine ridge in the Fortress Mountain Snow Laboratory located in the Canadian Rocky Mountains. Detailed maps of snow depth, snow depth change and snow- 
(a)

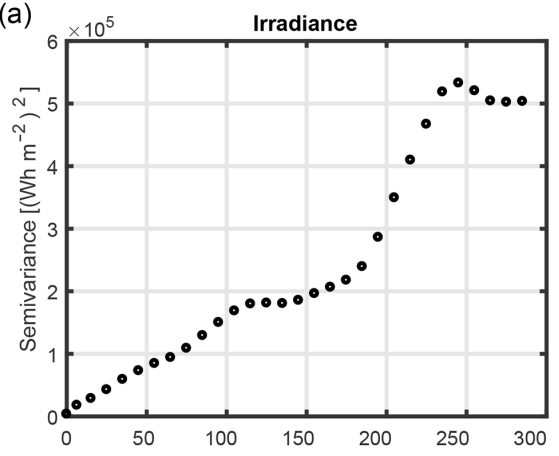

(c)

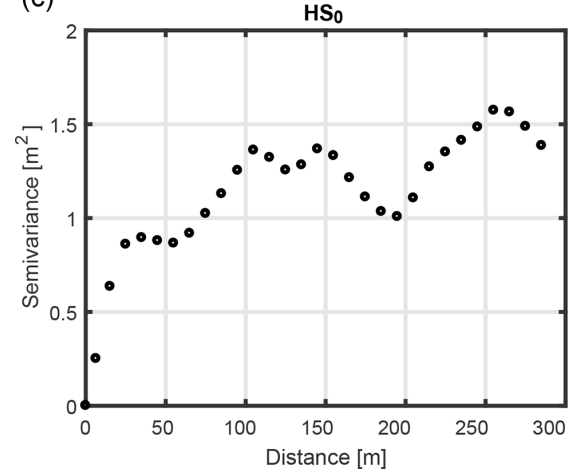

(b)

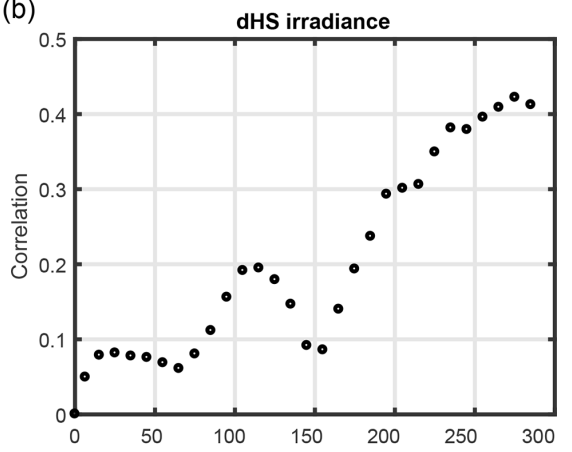

(d)

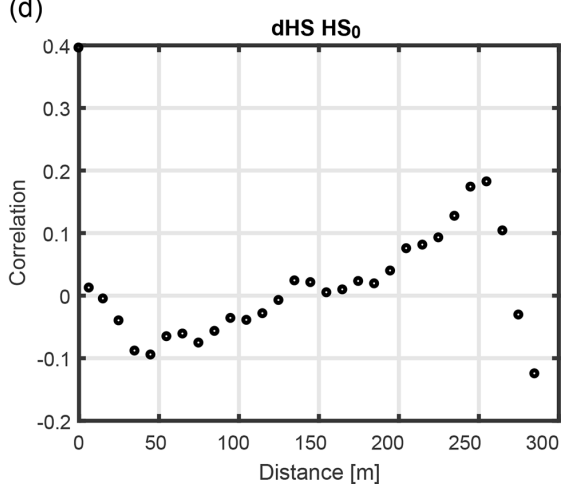

Figure 8. Correlograms of dHS with modelled irradiance and initial snow depth $\left(\mathrm{HS}_{0}\right)$, respectively $(\mathbf{b}, \mathbf{d})$. Variograms for $\mathrm{HS}_{0}$ and modelled irradiance $(\mathbf{a}, \mathbf{c})$.

covered area were generated during late season ablation using UAV-based orthophotos, photogrammetry and structurefrom-motion techniques. Snow depth and its change served as proxies for SWE and melt rates. Snow depth change values were found to be spatially variable and mainly dependent on variation in solar irradiance and albedo; they were also likely dependent on the cold content of the snowpack, which is a function of snow depth. Local and small-scale dust variations, which had not previously been observed in the area, increased the variability of ablation.

Snow-cover depletion curves were mostly dominated by the variability of the initial snow depth at the start of this study rather than the variability in snow depth change. Initial snow depth variability was approximately 5 times larger than the variability in snow depth change in this windswept environment. The scales of variability of snow depth and snow depth change were mismatched, with snow depth variability occurring at small scales $(<10 \mathrm{~m})$ and snow depth change associated with the medium scale $(50 \mathrm{~m})$ of albedo variation or the slope scale (100s of $\mathrm{m}$ ) of solar irradiance variation. As a result, the initial snow depth and changes in snow depth were not strongly correlated over space; thus, only initial snow depth influenced snow-cover depletion.

The observations collected here show the prerequisites for strong correlations that can impact snow-cover depletion curves. Correlation between melt and snow accumula- tion may be driven by cold content and melt energy distributions. Whilst cold content can create a negative correlation between melt and snow accumulation, melt energy variations can create either positive or negative correlations. In order to not compensate for each other, one process needs to be dominant, or the both processes need to create similar negative correlations. It is also important that these variations occur at the same spatial scales.

To further investigate these arguments, longer time series of spatially detailed snowpack and snow-cover observations need to be made in order to further test and examine the temporal evolution of the spatial covariance and variance of ablation and accumulation in various global alpine environments. The results of such a study could suggest how to parameterise snow-cover depletion and runoff models for snowmeltdominated alpine catchments, without relying on model calibration. This will help to transfer snow-hydrological models to ungauged catchments and to model future climate scenarios where snow redistribution patterns might be vastly different.

Data availability. The data are available upon request from the database manager (Amber Peterson) at the CCRN database: http: //www.ccrnetwork.ca/outputs/data/index.php (last access: 8 January 2020) (Changing Cold Regions Network Data, 2020). Please 
refer to the above-mentioned website for contact details. The data involve all UAV-derived grids for HS, dHS and SCA, as well as grids of explanatory variables (brightness, deviation from north and slope) at a $1 \mathrm{~m}$ resolution (cf. Sect. 2.4). Metadata are provided that explain the file naming convention of the grids (dates and variables).

Author contributions. JWP and MS conceived the study. MS collected field data, performed post-processing and analysis, and wrote the paper. JWP provided guidance and reviewed and revised the paper.

Competing interests. The authors declare that they have no conflict of interest.

Special issue statement. This article is part of the special issue "Understanding and predicting Earth system and hydrological change in cold regions". It is not associated with a conference.

Acknowledgements. The authors wish to acknowledge Phillip Harder for UAV training, Chris Marsh for post-processing and modelling support, May Guan and Angus Duncan for extensive field work help, Xing Fang for assistance with modelling CHRM results, as well as Phillip Harder, Jonathan Conway, Keith Musselman, Nico Leroux and Nik Aksamit for helpful comments and discussions. We are grateful for logistical support from Fortress Mountain Ski Resort, and are thankful to Cherie Westbrook for access to a differential GPS unit. Funding was provided by NSERC through "Discovery" and "Research Tools and Instruments" grants and NSERC's Changing Cold Regions Network, the Canada Research Chairs and Canada Excellence Research Chairs programmes, Alberta Innovation, Global Water Futures, and Alberta Agriculture and Forestry. We also want to acknowledge Charles Luce and two anonymous reviewers for their constructive work on the paper.

Financial support. This research has been supported by the NSERC (Discovery and Research Tools and Instruments grants and NSERC's Changing Cold Regions Network), the Canada Research Chairs and Canada Excellence Research Chairs programmes, Alberta Innovation, Global Water Futures, and Alberta Agriculture and Forestry.

Review statement. This paper was edited by Markus Weiler and reviewed by Charles Luce and two anonymous referees.

\section{References}

Anderton, S. P., White, S. M., and Alvera, B.: Evaluation of spatial variability in snow water equivalent for a high mountain catchment, Hydrol. Process., 18, 435-453, https://doi.org/10.1002/hyp.1319, 2004.

Blöschl, G. and Kirnbauer, R.: An analysis of snow cover patterns in a small alpine catchment, Hydrol. Process., 6, 99-109, https://doi.org/10.1002/hyp.3360060109, 1992.

Brauchli, T., Trujillo, E., Huwald, H., and Lehning, M.: Influence of Slope-Scale Snowmelt on Catchment Response Simulated With the Alpine3D Model, Water Resour. Res., 53, 10723-10739, https://doi.org/10.1002/2017WR021278, 2017.

Changing Cold Regions Network Data: http://www.ccrnetwork.ca/ outputs/data/index.php, last access: 8 January 2020.

Clark, M. P., Hendrikx, J., Slater, A. G., Kavetski, D., Anderson, B., Cullen, N. J., Kerr, T., Hreinsson, E.Ö., and Woods, R. A.: Representing spatial variability of snow water equivalent in hydrologic and land-surface models: A review, Water Resour. Res., 47, W07539, https://doi.org/10.1029/2011WR010745, 2011.

DeBeer, C. M. and Pomeroy, J. W.: Modelling snow melt and snowcover depletion in a small alpine cirque, Canadian Rocky Mountains, Hydrol. Process., 23, 2584-2599, https://doi.org/10.1002/hyp.7346, 2009.

DeBeer, C. M. and Pomeroy, J. W.: Simulation of the snowmelt runoff contributing area in a small alpine basin, Hydrol. Earth Syst. Sci., 14, 1205-1219, https://doi.org/10.5194/hess-14-12052010, 2010.

Deems, J. S., Fassnacht, S. R., and Elder, K. J.: Fractal distribution of snow depth from LiDAR data, J. Hydrometeorol., 7, 285-297, https://doi.org/10.1175/JHM487.1, 2006.

Dornes, P. F., Pomeroy, J. W., Pietroniro, A., Carey, S. K., and Quinton, W. L.: Influence of landscape aggregation in modelling snow-cover ablation and snowmelt runoff in a subarctic mountainous environment, Hydrolog. Sci. J., 53, 725-740, https://doi.org/10.1623/hysj.53.4.725, 2008a.

Dornes, P. F., Pomeroy, J. W., Pietroniro, A., and Verseghy, D. L.: Effects of spatial aggregation of initial conditions and forcing data on modeling snowmelt using a land surface scheme, J. Hydrometeorol., 9, 789-803, https://doi.org/10.1175/2007JHM958.1, 2008b.

Egli, L., Jonas, T., Grünewald, T., Schirmer, M., and Burlando, P.: Dynamics of snow ablation in a small Alpine catchment observed by repeated terrestrial laser scans, Hydrol. Process., 26, 15741585, https://doi.org/10.1002/hyp.8244, 2012.

Elder, K., Rosenthal, W., and Davis, R. E.: Estimating the spatial distribution of snow water equivalence in a montane watershed, Hydrol. Process., 12, 1793-1808, https://doi.org/10.1002/hyp.5586, 1998.

Essery, R. and Pomeroy, J.: Implications of spatial distributions of snow mass and melt rate for snow-cover depletion: theoretical considerations, Ann. Glaciol., 38, 261-265, https://doi.org/10.3189/172756404781815275, 2004.

Fang, X., Pomeroy, J. W., Ellis, C. R., MacDonald, M. K., DeBeer, C. M., and Brown, T.: Multi-variable evaluation of hydrological model predictions for a headwater basin in the Canadian Rocky Mountains, Hydrol. Earth Syst. Sci., 17, 1635-1659, https://doi.org/10.5194/hess-17-1635-2013, 2013.

Gray, D. M. and Male, D. H. (Eds.): Handbook of snow: principles, processes, management and use, Pergamon, Toronto, 1981. 
Grünewald, T., Schirmer, M., Mott, R., and Lehning, M.: Spatial and temporal variability of snow depth and ablation rates in a small mountain catchment, The Cryosphere, 4, 215-225, https://doi.org/10.5194/tc-4-215-2010, 2010.

Harder, P., Schirmer, M., Pomeroy, J., and Helgason, W.: Accuracy of snow depth estimation in mountain and prairie environments by an unmanned aerial vehicle, The Cryosphere, 10, 2559-2571, https://doi.org/10.5194/tc-10-2559-2016, 2016.

Helbig, N., van Herwijnen, A., Magnusson, J., and Jonas, T.: Fractional snow-covered area parameterization over complex topography, Hydrol. Earth Syst. Sci., 19, 1339-1351, https://doi.org/10.5194/hess-19-1339-2015, 2015.

Liston, G. E.: Interrelationships among snow distribution, snowmelt and snow cover depletion: implications for atmospheric, hydrologic and ecologic modelling, J. Appl. Meteorol., 38, 1474-1487, https://doi.org/10.1175/15200450(1999)038<1474:IASDSA>2.0.CO;2, 1999.

Liston, G. E.: Representing subgrid snow cover heterogeneities in regional and global models, J. Climate, 17, 1381-1397, https://doi.org/10.1175/15200442(2004)017<1381:RSSCHI>2.0.CO;2, 2004.

Liston, G. E. and Sturm, M.: A snow-transport model for complex terrain, J. Glaciol., 44, 498-516, https://doi.org/10.1002/(SICI)10991085(199910)13:14/15<2423::AID-HYP853>3.0.CO;2-U, 1998.

Luce, C. H., Tarboton, D. G., and Cooley, K. R.: The influence of the spatial distribution of snow on basin-averaged snowmelt, Hydrol. Process., 12, 1671-1683, https://doi.org/10.1002/(SICI)10991085(199808/09)12:10/11<1671::AID-HYP688>3.0.CO;2-N, 1998.

Luce, C. H., Tarboton, D. G., and Cooley, K. R.: Subgrid parameterization of snow distribution for an energy and mass balance snow cover model, Hydrol. Process., 13, 1921-1933, https://doi.org/10.1002/(SICI)10991085(199909)13:12/13\%3C1921::AID-HYP867\%3E3.0.CO;2S, 1999.

MacDonald, M. K., Pomeroy, J. W., and Pietroniro, A.: On the importance of sublimation to an alpine snow mass balance in the Canadian Rocky Mountains, Hydrol. Earth Syst. Sci., 14, 14011415, https://doi.org/10.5194/hess-14-1401-2010, 2010.

Marks, D. and Dozier, J.: Climate and energy exchange at the snow surface in the alpine region of the Sierra Nevada: 2. Snowcover energy balance, Water Resour. Res., 28, 3043-3054, https://doi.org/10.1029/92WR01483, 1992.

Mott, R., Schirmer, M., Bavay, M., Grünewald, T., and Lehning, M.: Understanding snow-transport processes shaping the mountain snow-cover, The Cryosphere, 4, 545-559, https://doi.org/10.5194/tc-4-545-2010, 2010.

Mott, R., Egli, L., Grünewald, T., Dawes, N., Manes, C., Bavay, M., and Lehning, M.: Micrometeorological processes driving snow ablation in an Alpine catchment, The Cryosphere, 5, 1083-1098, https://doi.org/10.5194/tc-5-1083-2011, 2011.

Mott, R., Gromke, C., Grünewald, T., and Lehning, M.: Relative importance of advective heat transport and boundary layer decoupling in the melt dynamics of a patchy snow cover, Adv. Water Resour., 55, 88-97, https://doi.org/10.1016/j.advwatres.2012.03.001, 2013.
Mott, R., Paterna, E., Horender, S., Crivelli, P., and Lehning, M.: Wind tunnel experiments: cold-air pooling and atmospheric decoupling above a melting snow patch, The Cryosphere, 10, 445458, https://doi.org/10.5194/tc-10-445-2016, 2016.

Musselman, K. N., Pomeroy, J. W., Essery, R. L. H., and Leroux, N.: Impact of windflow calculations on simulations of alpine snow accumulation, redistribution and ablation, Hydrol. Process., 29, 3983-3999, https://doi.org/10.1002/hyp.10595, 2015.

Painter, T. H., Deems, J. S., Belnap, J., Hamlet, A. F., Landry, C. C., and Udall, B.: Response of Colorado River runoff to dust radiative forcing in snow, P. Natl. Acad. Sci. USA, 107, 1712517130, https://doi.org/10.1073/pnas.0913139107, 2010.

Painter, T. H., Berisford, D. F., Boardman, J. W., Bormann, K. J., Deems, J. S., Gehrke, F., Hedrick, A., Joyce, M., Laidlaw, R., Marks, D., Mattmann, C., McGurk, B., Ramirez, P., Richardson, M., McKenzie Skiles, S., Seidel, F. C., and Winstral, A.: The Airborne Snow Observatory: Fusion of scanning lidar, imaging spectrometer, and physically-based modeling for mapping snow water equivalent and snow albedo, Remote Sens. Environ., 184, 139-152, https://doi.org/10.1016/j.rse.2016.06.018, 2016.

Pomeroy, J. and Gray, D.: Snowcover-accumulation, relocation and management, Report No. 7, National Hydrology Research Institute Science, Saskatoon, Canada, 1995.

Pomeroy, J. W., Gray, D. M., Shook, K. R., Toth, B., Essery, R. L. H., Pietroniro, A., and Hedstrom, N.: An evaluation of snow accumulation and ablation processes for land surface modelling, Hydrol. Process., 12, 2339-2367, https://doi.org/10.1002/(SICI)10991085(199812)12:15<2339::AID-HYP800>3.0.CO;2-L, 1998.

Pomeroy, J. W., Hanson, S., and Faria, D.: Small-scale variation in snowmelt energy in a boreal forest: an additional factor controlling depletion of snow cover, P. East. Snow Conf., 58, 85-96, https://doi.org/10.3189/172756404781815275, 2001.

Pomeroy, J. W., Toth, B., Granger, R. J., Hedstrom, N. R., and Essery, R. L. H.: Variation in surface energetics during snowmelt in a subarctic mountain catchment, J. Hydrometeorol., 4, 702-719, https://doi.org/10.1175/15257541(2003)004<0702:VISEDS>2.0.CO;2, 2003.

Pomeroy, J., Essery, R., and Toth, B.: Implications of spatial distributions of snow mass and melt rate for snow-cover depletion: observations in a subarctic mountain catchment, Ann. Glaciol., 38, 195-201, https://doi.org/10.3189/172756404781815275, 2004.

Pomeroy, J. W., Fang, X., and Marks, D. G.: The cold rain-onsnow event of June 2013 in the Canadian Rockies - characteristics and diagnosis, Hydrol. Process., 30, 2899-2914, https://doi.org/10.1002/hyp.10905, 2016.

Rose, A.: The Visual Process, in: Vision: Human and Electronic, Plenum Press, New York, 1-28, 1973.

Schirmer, M. and Lehning, M.: Persistence in intra-annual snow depth distribution: 2. Fractal analysis of snow depth development, Water Resour. Res., 47, W09516, https://doi.org/10.1029/2010WR009429, 2011.

Schirmer, M., Wirz, V., Clifton, A., and Lehning, M.: Persistence in intra-annual snow depth distribution: 1. Measurements and topographic control, Water Resour. Res., 47, W09517, https://doi.org/10.1029/2010WR009426, 2011.

Shook, K. and Gray, D. M.: Small-scale spatial structure of shallow snowcovers, Hydrol. Process., 10, 1283-1292, 1996. 
Skiles, S. M., Painter, T. H., Belnap, J., Holland, L., Reynolds, R. L., Goldstein, H. L., and Lin, J.: Regional variability in dust-on-snow processes and impacts in the Upper Colorado River Basin, Hydrol. Process., 29, 5397-5413, https://doi.org/10.1002/hyp.10569, 2015.

Trujillo, E., Ramírez, J. A., and Elder, K. J.: Topographic, meteorologic, and canopy controls on the scaling characteristics of the spatial distribution of snow depth fields, Water Resour. Res., 43, W07409, https://doi.org/10.1029/2006WR005317, 2007.

Wayand, N. E., Marsh, C. B., Shea, J. M., and Pomeroy, J. W.: Globally scalable alpine snow metrics, Remote Sens. Environ., 213, 61-72, https://doi.org/10.1016/j.rse.2018.05.012, 2018.

Webster, R. and Oliver, M.: Geostatistics for Environmental Scientists, John Wiley \& Sons Ltd, Chichester, UK, 2007.
Westoby, M., Brasington, J., Glasser, N., Hambrey, M., and Reynolds, J.: "Structure-from-Motion" photogrammetry: A lowcost, effective tool for geoscience applications, Geomorphology, 179, 300-314, https://doi.org/10.1016/j.geomorph.2012.08.021, 2012.

Winstral, A. and Marks, D.: Simulating wind fields and snow redistribution using terrain-based parameters to model snow accumulation and melt over a semi-arid mountain catchment, Hydrol. Process., 16, 3585-3603, https://doi.org/10.1002/hyp.1238, 2002.

Winstral, A. and Marks, D.: Long-term snow distribution observations in a mountain catchment: Assessing variability, time stability, and the representativeness of an index site, Water Resour. Res., 50, 293-305, https://doi.org/10.1002/2012WR013038, 2014. 